\title{
Removal of fine iron-oxide particles after post-filtration in local potable water using an electrophoretic method
}

\begin{abstract}
Potable water from several residential areas on the east coast of Malaysia was filtered using a polyethersulphone (PES) membrane to separate the coarse and fine iron-oxide particles inside the pipelines. The as-received samples consisted of a wide distribution of particle sizes, ranging from $5 \mathrm{\varepsilon m}$ to $400 \mathrm{~nm}$. The concentration of fine iron-oxide particles inside a distribution system was extremely low. Hence, a specific method is necessary to concentrate and separate the fine particles from the coarse ones. To study the fine particles from the bulk, excess pressure was applied to the membrane filter so that the clogged particles were released into the permeate. A $100 \mathrm{kDa}$ PES membrane was used to separate the particles, because the samples consisted of a wide molecular-weight cut-off range from $89 \mathrm{~g} / \mathrm{mol}$ goethite ( $\breve{U}$ $\mathrm{FeOOH})$ to $231 \mathrm{~g} / \mathrm{mol}$ hematite $(\mathrm{Fe} 2 \mathrm{O} 3)$. After the filtration process, the size distribution of permeated particles reduced to $550 \mathrm{i} 400 \mathrm{~nm}$. Through X-ray diffraction analysis, numerous polymorphs such as ÜFeOOH, $\mathrm{Fe} 3 \mathrm{O} 4, \mathrm{Fe} 2 \mathrm{O} 3$ and maghemite were detected from the samples. The zeta potential value of the permeated particles changed from ī 18.5 to $\overline{1} 13 \mathrm{mV}$, suggesting that the dispersity of permeated iron-oxide particles became unstable, but remained adequate for electrophoretic deposition (EPD). The fibrous carbon electrode used in the EPD process, could remove up to $87 \%$ of the permeated iron-oxide particles compared to solid carbon electrodes $(<56 \%)$. A high-surface-area, porous electrode and a moderate applied voltage were preferred in order to minimise gas formation, reduce the electro-osmosis effect and increase the deposition efficiency.
\end{abstract}

Keyword: Electrophoretic deposition; Fibre electrodes; Limiting flux; Iron oxide; Zeta potential 